\title{
Problems in the Value Evaluation of Cultural Enterprises Against the Background of Big Data and Its Countermeasures*
}

\author{
Yaping Huang \\ Fuzhou University of International Studies and Trade \\ Fuzhou, China 350202
}

\author{
Yina Chen \\ Fuzhou University of International Studies and Trade \\ Fuzhou, China 350202 \\ Haijun Kang** \\ Fuzhou University of International Studies and Trade \\ Fuzhou, China 350202 \\ **Corresponding Author
}

\author{
Zhirong Liu \\ Fuzhou University of International Studies and Trade \\ Fuzhou, China 350202 \\ Yao Chen \\ Fujian Xingmin Assets Appraisal \& Land Real Estate \\ Appraisal Co., Ltd. \\ Fuzhou, China 350002
}

\begin{abstract}
Due to the particularity of economic profit of cultural enterprises, the value evaluation of cultural enterprises has always been a controversial hot issue in China. With the rapid development of modern science and technology, big data has built a better platform for asset evaluation and opened a new door for enterprise value evaluation. The development of big data will bring huge promotion space to the value evaluation of cultural enterprises, and solve the problems of selecting important parameters of enterprise value evaluation and reducing the subjectivity of evaluation results. Based on the current trend of cultural enterprise value evaluation under the background of big data, this paper analyzes the opportunities and challenges brought by big data to the evaluation of cultural enterprise value, and puts forward the improvement direction of cultural enterprise value evaluation.
\end{abstract}

Keywords - big data; cultural enterprise; value evaluation

\section{INTRODUCTION}

The development of cultural enterprises is an important way to promote the adjustment of China's economic structure and accelerate the transformation of economic development mode. As a new industry, most of the assets of cultural enterprises are intangible assets, including copyright, trademark right, patent right and goodwill, etc. The diversity, exclusiveness, commonweal and Technological Substitution of the right combination make it difficult to evaluate the value of cultural enterprises. As a new modern information technology, big data can effectively collect and analyze massive data. The application of big data in enterprise value evaluation will be a

*Fund: 2019 national innovation and entrepreneurship training program for college students "Research on enterprise value evaluation and development trend in the context of big data era" (201913762011) force that can't be ignored. Everyone knows, the enterprise value evaluation needs to check the assets and liabilities on and off the balance sheet of the enterprise, which is a work that consumes time and energy. However, the use of big data analysis technology can greatly improve the efficiency of data collection and collation, and introduce many new big data mathematical statistical models to replace manual analysis, so that the appraisers can be scientific, fast and accurate carry out assessment, simplify assessment procedure and ensure assessment quality.

\section{CURRENT Situation OF CUlTURAL ENTERPRISE VALUE EVALUATION INDUSTRY}

As one of the emerging industries, the value evaluation of cultural enterprises is still in its infancy in China. The domestic research on asset evaluation has a mature framework, but there are not many researches on the evaluation of intellectual property, intangible assets and patent rights. The three methods of traditional assets evaluation, namely market method, income method and cost method, can be applied to the evaluation of intangible assets. Reasonable parameters can be selected to evaluate intellectual property assets from different perspectives, but the internal value of intangible assets cannot be reasonably and comprehensively quantified [1]. Due to the weak correspondence of the cost of intangible assets, it is difficult to obtain and measure the cost of intangible assets of enterprises, so the cost method is not widely used in the value evaluation of cultural enterprises. In the market method, it is not easy to find similar cultural enterprise transaction cases. Even if a qualified transaction case is found, both parties of the transaction usually keep their transaction information strictly confidential and do not disclose it to the public easily, which brings some 
restrictions to the use of the market method. In the income method, it is relatively difficult to determine the important parameters such as free cash flow and weighted average cost of capital, which are easily affected by human subjective factors. In 2008, the China Assets Appraisal Association issued the Assets appraisal criteria -intangible assets, which were revised in 2017. In 2016, it issued the Guidance on intangible assets appraisal of cultural enterprises. At the same time, in 2016, the state issued the Law of assets appraisal the People's Republic of China to improve the laws and regulations, indicating that there are corresponding assets appraisal criteria for cultural enterprises in the asset appraisal industry as a guide, the research on the legal system of assets evaluation criteria also has a relatively complete prototype. The combination of cultural enterprises and asset evaluation is a new field. It is of great significance for the common development of cultural enterprises and asset evaluation industry to apply the value evaluation research of cultural enterprises to the social and economic development.

\section{Opportunities Brought by Big Data to the VAlue EVALUATION OF CULTURAL ENTERPRISES}

\section{A. Providing New Ideas for the Value Evaluation of Cultural Enterprises}

In the production and marketing process of movie and TV series, Google has begun to use the new big data analysis model of "quantifying movie magic with Google search" to evaluate and analyze the weekend movie box office, and reasonably use the analysis results of Internet big data to avoid box office failure. The establishment of the model and the accuracy of the data make it possible to reasonably predict the box office income of the film and television enterprises. To a certain extent, it brings new inspiration to the evaluation of the value of the film and television enterprises. It urges the appraisers to improve the accuracy of the prediction of the box office income of the film on the basis of the big data analysis platform, and provides the market basis for the evaluation of the value of the cultural enterprises. Not only that, in terms of the value evaluation of copyright assets, the appraisers, on the basis of traditional valuation technology, combined with big data technology to evaluate "copyright fragments", transformed cultural assets into data through the Internet for trading, dynamically predicted and analyzed the value indicators of the obtained data of related factors, and quantitatively estimated the value of copyright. For example, Yachang group establishes the Yachang coefficient (AAMI) according to the auction data of "China art auction market quotation publishing system", which to some extent reflects the current price trend and operation of the art market. Art collectors and investors can value the collection according to the index [2]. The appraisers can also adopt similar ideas, use the data statistical model to compile, obtain important parameters, have a clearer grasp of the copyright market price, and make the results of cultural enterprise value evaluation more scientific. Today's cultural enterprise value evaluation, big data technology makes rapid quantitative evaluation and screening possible. Based on big data mining, it can help evaluators quickly select data that conforms to the established value index system from massive data, realize the cumulative correlation analysis of customer experience and consumer behavior, and predict and evaluate the value of cultural enterprises from multiple perspectives. It can be seen that big data has opened up a new way for appraisers to evaluate the value of cultural enterprises.

\section{B. Improving the Efficiency and Accuracy of Evaluation}

It will take several days or even months for the appraisers to evaluate an asset from macro policy analysis, collection of relevant information, on-the-spot investigation and audit to the determination of calculation methods. Moreover, there are many kinds of assets in cultural enterprises, among which the exclusiveness, non substantiality and efficiency and so on of intangible assets make the evaluation more difficult. However, in the era of big data, the use of computers and the Internet makes it possible to quickly obtain the data needed for evaluation. The collection and processing of information and its application in the evaluation of cultural enterprise value can simplify the evaluation process, reduce the time and greatly improve the work efficiency. And the important evaluation parameters can avoid the mistakes in the process of manual processing of information to a certain extent under the accurate prediction of computer technology and statistical model, can improve the processing accuracy of big data in asset evaluation, and to a large extent overcome the dependence of traditional cultural enterprises on the personal level and experience of the appraisers.

\section{Improving the Competitiveness of Evaluation Industry}

With the innovation and evolution of the asset evaluation industry in the Internet wave, there will inevitably be more fierce competition. Existing competitors will also work together to win-win cooperation and survival of the fittest. With the development of cloud valuation business, evaluation agencies and platforms in business scope, accurate evaluation, data monopoly, reputation, after-sales service and other fields are in full swing competition. The experience of users in different fields is different, and the advantages and disadvantages corresponding to the evaluation organization can also be reflected [3]. In addition, broadening the scope of business is an important means to improve the competitiveness of evaluation institutions. With the vigorous development of cultural enterprises, the economic activities of enterprises are increasing day by day. Many aspects such as merger and division, auction and lease, bankruptcy and dissolution of enterprises need professional services for asset evaluation [3]. The existing appraisal institutions are aware of the importance of expanding the scope of appraisal business, catering to the market demand of cultural enterprises for assets appraisal, providing data assets mortgage loan, data assets securitization, data assets insurance and other services, mining the deep value of cultural enterprises as much as possible, improving the competitiveness of the asset industry, and developing together with cultural enterprises. 
enterprises and related platforms, but also affect the future results of enterprise value evaluation, which is a wake-up call for the application of big data in the asset evaluation industry.

\section{A. Weak Big Data Application Capabilities Restrict Evaluation Development}

On the one hand, from the perspective of scientific and technological conditions, the traditional data can't be compared in terms of the number of big data or the update speed. At present, the technical problems faced by the evaluation industry include low data utilization, single function of information products, and less update of enterprise websites, which are not conducive to the collaborative cooperation of internal information circulation. Only a few enterprises build efficient OA system or publicity website, but most of them use office software. On the other hand, from the perspective of the degree of data access, today's database use mode is pay as quantity, not completely open for free use. For example, domestic wind database, China business product research institute, CNKI and NIST defined cloud computing and other databases all need users to register and $\log$ in to their platforms, pay according to usage, which limits the free access of data and increases the cost of evaluation.

\section{B. Incomplete Application Environment of Big Data Impacts the Assessment Results}

Big data needs strong analysis ability of users, and only reasonable and appropriate use can maximize its value, which requires the appraisers to systematically master the theoretical knowledge and practical ability related to data analysis, and skillfully use software tools. But up to now, the talents who master these skills are scarce, and the immature industrial talent structure is a huge challenge to big data. From the perspective of the rules and regulations of cultural enterprises, the management rules and regulations related to the application of big data are relatively weak, and at present, there is no special organization to collect, sort and analyze the big data of cultural industry, and then the intellectual property cultural enterprises of data cannot provide a comprehensive and effective guarantee mechanism. All of these make it more difficult to evaluate the value of cultural enterprises. In the future, the proportion of cultural enterprises will be larger and larger, but the lack of talents and systems has launched a challenge to the value evaluation of cultural enterprises.

\section{The Data Security Issues Impact Assessment Results}

Even in the face of massive data, it is one of the characteristics of big data that can truly and comprehensively reflect the facts. However, in the process of practical application, the forged data is inevitably mixed in the massive data, so it is difficult to identify the authenticity. For example, false click through rate, box office data, reviews and other situations often occur during the period of film and television works reflection. Not long ago, the media "Xiao Sheng Bi Bi" revealed that the data of "Wasp's nest" in the tourism community was not genuine. According to the data report provided by the data team of Hurui, $85 \%$ of the 21 million "real reviews" of Wasp's nest were copied, including 5.72 million food reviews and 12.21 million hotel reviews. This will not only damage the interests of users, reduce the reputation of

\section{STRATEGIC RESPONSE TO THE DEVELOPMENT OF CUltural ENTERPRISES AgAinst THE BACKGROUND OF BIG DATA}

\section{A. Building Data Sharing Platform and Improving Application Ability}

In order to strengthen the information construction of the evaluation industry and improve the ability of asset evaluation to control the era of big data, the construction of data platform is essential. The evaluation industry should establish and improve the industry database, unify the information system construction standards of various institutions, and cooperate with professional research companies to expand information sources. Make effective use of modern information technology such as big data, give full play to the advantages of information resource network system to form a comprehensive database, ensure sufficient evaluation reference data, and promote the development of Internet platform in asset evaluation industry [4]. At the same time, it applies big data to the analysis of market prospect and profit model of cultural enterprises, and makes dynamic analysis of customer experience value data, and scientifically evaluates the value of cultural enterprises realization.

\section{B. Training Comprehensive Talents}

In order to cultivate comprehensive talents, it is necessary to set up related majors of asset evaluation in Colleges and universities, expand the publicity of the future development prospect of asset evaluation, attract more excellent talents to participate in the evaluation career, improve the continuing education mechanism of appraisers, and train excellent professional appraisers. At the same time, the assets appraisal industry should actively carry out the appraisal work of cultural enterprises, regularly train the appraisers on the latest theoretical achievements of cultural assets appraisal, gradually improve the ability and level of the assets appraisers, promote the transformation of theories to achievements, and guide the appraisal practice. At the same time, due to the emergence of the new data model, the mathematical statistics and computer technology of the assets appraisers are also put forward more stringent requirements. In the process of talent team building, it can focus on the cultivation of data integration and analysis ability of asset appraisers, the application of new economic model and the efficient and accurate prediction ability of asset value.

\section{Improving Relevant Systems}

The state should improve a series of evaluation systems on intangible assets management and supervision of cultural enterprises, issue guidance on strengthening the management of cultural enterprises' assets, coordinate the accounting standard setting departments, strengthen the research on the evaluation and measurement of the fair value of cultural assets, and timely issue relevant policies. China Assets Appraisal from the perspective of value discovery, evaluation and 
[4] Zhang Bo, Lei Jin, Ren dianshun. Value Discovery and Activation of Retained Content in traditional Publishing From the Perspective of Data Assets [J]. Science \& Technology and Publishing, 2018, (10): 140-147. (in Chinese)

Association should also, on the basis of the original intangible assets appraisal related standards, formulates the relevant appraisal standards for the characteristics of cultural enterprise assets, further guides and standardizes the cultural enterprise assets appraisal behavior, better plays the role of the third party of the assets appraisal institution, improves the credibility of the assets appraisal industry, scientifically reflects the value of cultural assets, provides better services for the value of cultural enterprises and promotes the healthy and rapid development of cultural enterprises and appraisal industry [5].

\section{Strengthening Data Security Management}

For enhancement of the security of Internet information and data, first of all, it is necessary to strengthen the construction of technical protection facilities. When purchasing electronic equipment, computer equipment and other equipment, it should ensure that there are regular protection and anti-virus software in the equipment and meet the national security requirements [5]. Secondly, the intelligent terminal can be strengthened by a series of advanced information security technologies such as cloud technology and big data tools, so as to fundamentally defend hacker attacks, troubleshoot system vulnerabilities, eliminate network viruses, discover and solve network security threats in time, and reduce the occurrence of abnormal risks. Finally, the assets appraisal institution should establish and improve the data security management system, develop relevant technical support, detect the risk of database system, check the fake data, avoid the occurrence of data leakage, and guarantee the application of big data for the appraisers. At the same time, industry associations and relevant departments should also realize the importance of data security risks, formulate relevant regulations to regulate the operation of the industry and ensure data security [5].

\section{CONCLUSION}

With the vigorous development of the government, the development of cultural enterprises has opened a new page, asset evaluation has also ushered in a new reform point in the background of big data era, gradually catching up with the pace of the Internet economy era. The integration and development of big data and asset value evaluation industry is not only an opportunity but also a challenge. The asset evaluation industry should grasp the new pulse of the times, innovate the way of practice, improve the ability of practice, and improve the service level. At the same time, it should also strengthen the awareness of risk prevention, conform to the trend of the times, and bravely meet the new challenges, so as to achieve longterm and good development and open up new chapter of the industry.

\section{REFERENCES}

[1] Su Wenrong. Application of Big Data in Cultural Assets Evaluation [J]. Cooperative Economy and Science \&Technology, 2018, (14): 144-145. (in Chinese)

[2] Zhang Li. Research on Enterprise Customer Asset Value Evaluation in the Era of Big Data [J]. Friends of Accounting, 2018, (17): 133-135. (in Chinese)

[3] Yang Lu, Li Li. Talking About the Application of Big Data in asset Evaluation [J]. China Asset Appraisal, 2015, (6): 41-44. (in Chinese)
[5] Zhang Jinjuan, Wang Yulan. The Impact and Countermeasures of Internet Development on Asset Appraisal Industry [J]. Theory and Modernization, 2017, (6): 41-44. (in Chinese) 